\title{
Cancer and Coagulation
}

\author{
Alok A. Khorana, M.D. ${ }^{1}$ \\ ${ }^{1}$ James P. Wilmot Cancer Center, and the Department of Medicine, University of Rochester, \\ Rochester, N.Y
}

\section{Abstract}

Thromboembolism, including both venous and arterial events, occurs commonly amongst patients with cancer. The occurrence of thromboembolism has significant consequences for cancer patients, including direct and indirect associations with mortality, morbidity, requirement for longterm anticoagulant therapy and consumption of healthcare resources. Recent studies have resulted in a better understanding of clinical risk factors and biomarkers of cancer-associated thrombosis, and a risk assessment model incorporating both has now been validated in multiple settings. Thromboprophylaxis with either unfractionated heparin or low-molecular-weight heparins (LMWHs) has been shown to be safe and effective in high-risk settings such as hospitalization for medical illness and the post-surgical period. Emerging new data from randomized studies have focused on outpatient prophylaxis, suggesting potential benefits in this setting as well. Treatment of cancer-associated thrombosis requires long-term anticoagulation with LMWH. Results from ongoing and planned trials of novel anticoagulants in the cancer setting are awaited.

\section{Keywords}

venous thromboembolism; prevention; treatment; risk factors; cancer

Thromboembolism is common amongst patients with a diagnosis of malignancy, particularly those receiving active therapy. Thromboembolic events can be venous or arterial. Venous events include deep vein thrombosis (DVT), pulmonary embolism (PE) together categorized as venous thromboembolism (VTE). Arterial events, include stroke, myocardial infarction and arterial embolism. Both venous and arterial events have increased substantially in frequency in recent years ${ }^{1}$, with "unacceptably high" event rates documented in the most contemporary studies ${ }^{2,3}$.

There are significant consequences to the occurrence of thromboembolism in this setting: requirement for long-term anticoagulation, a $12 \%$ annual risk of bleeding complications, an up to $21 \%$ annual risk of recurrent $\mathrm{VTE}^{4}$ and potential impact on chemotherapy delivery and patient quality of life. Most importantly, thrombotic events are the second leading cause of death in cancer patients (after cancer itself), and are associated with decreased short-term and long-term survival ${ }^{5-7}$. Finally, the occurrence of VTE leads to the consumption of significant healthcare resources ${ }^{8}$. This review will focus on prevalence, risk assessment, prevention and treatment of cancer-associated thrombosis, with an emphasis on new and emerging data. 


\section{PREVALENCE AND RISK}

\section{Prevalence}

Actual rates of VTE vary widely between published reports. This is related to differences between studies in the type of population studied, duration of follow-up, definition of thromboembolic events and active versus passive ascertainment ${ }^{9-11}$. In addition, rates are higher in more contemporary reports, particularly from the United States (US). For instance, in an analysis of 17,284 commercially insured US patients with cancer and a matched control cohort, $12.6 \%$ of patients in the cancer cohort and $1.4 \%$ in the control cohort developed $\mathrm{VTE}^{3}$. Similarly, in a large recent retrospective analysis of 932 patients receiving cisplatin-based treatment, $169(18.1 \%)$ experienced a thromboembolic event during treatment or within 4 weeks of the last dose $^{2}$. In contrast, in two large studies of thromboprophylaxis conducted primarily outside the US, rates in the control arms were quite low (3.9\% and 3.4\% in the PROTECHT and SAVE-ONCO studies, respectively) $)^{12,13}$.

\section{Risk Factors}

Clinical risk factors for VTE can be categorized as patient-related, cancer-related and treatment-related risk factors (Table 1). Patient-related risk factors include older age, race/ ethnicity (higher risk in African-Americans and lower in Asians), and presence of comorbid conditions (particularly infection, renal or pulmonary disease and obesity; rates increase with increase in the Charlson Comorbidity Index $)^{1,3,14}$. The primary site of cancer is an especially important risk factor, with highest rates observed in patients with brain, pancreas, stomach, kidney, ovary and lung cancers ${ }^{9}$. Patients with hematologic malignancies (particularly lymphoma and myeloma) are also at high risk (in one study, odds ratio [OR] $28,95 \%$ CI $4.0-199.7)^{15}$. The rate of VTE varies during the natural history of the malignancy. In a population-based study, risk of VTE was highest in the first 3 months after initial diagnosis of cancer (OR 53.5, 95\% CI 8.6-334.3), although some degree of elevated risk persisted for years ${ }^{15}$.

Therapeutic interventions enhance the risk of VTE in cancer. Cancer patients undergoing surgery have a two-fold increased risk of postoperative VTE as compared to non-cancer patients, and this elevation in risk can persist for a period up to 7 weeks ${ }^{16}$. Hospitalization also substantially increases the risk of developing VTE in cancer patients (OR 2.34, 95\% CI $1.63-3.36)^{17}$. The use of systemic chemotherapy is associated with a 2-to 6-fold increased risk of VTE compared to the general population ${ }^{18,19}$. Anti-angiogenic agents, particularly thalidomide and lenalidomide, have been associated with high rates of VTE when given in combination with dexamethasone or chemotherapy. Bevacizumab-containing regimens have been associated with increased risk for an arterial thromboembolic event (hazard ratio [HR] 2.0, 95\% CI 1.05-3.75) but the data for risk of VTE are conflicting ${ }^{20,21}$. Sunitinib and sorafenib, agents targeting the angiogenesis pathway, have also similarly been associated with elevated risk for arterial (but not venous) events [RR 3.03 (95\% CI, 1.25 to 7.37) $]^{22}$.

\section{Biomarkers}

A variety of biomarkers have been identified in recent prospective and retrospective reports as being potentially predictive of VTE (Table 1). Baseline (pre-chemotherapy) elevated platelet and leukocyte counts, and low hemoglobin levels have all been demonstrated to be risk factors for chemotherapy-associated $\mathrm{VTE}^{23,24}$. These components of the complete blood count are already available for nearly all cancer patients and therefore can be considered to be extremely cost-effective biomarkers and do not require specialized laboratory setups. 
D-dimer is another widely studied biomarker predictive of cancer-associated VTE. In colorectal cancer, patients with elevated D-dimer (defined as $>0.3 \mathrm{mg} / \mathrm{L}$ ) had a $20 \%(95 \%$ CI, 12 to $31 \%$ ) one-year incidence of DVT versus 5\% (95\% CI, 2 to 12\%) for other patients (adjusted HR 6.53; 95\% CI, 1.58 to 27.0) ${ }^{25}$. Elevated D-dimer was also associated with increased risk of VTE (HR $=1.8 ; 95 \%$ CI, 1.0 to $3.2 ; p=.048$ ) in the Vienna CATS registry ${ }^{26}$. D-dimer is also widely available in most laboratories and therefore has practical utility as a biomarker.

Tissue factor (TF), the physiologic initiator of hemostasis, is also widely expressed across a variety of human malignancies and released into the circulation in the form of microparticles; levels can be detected in cancer patients ${ }^{27}$. Assays to evaluate TF include immunohistochemical grading of TF expression on tumor cells ${ }^{28}$, measurement of TF antigen using ELISA ${ }^{29}$, TF microparticle procoagulant activity ${ }^{30}$ or impedance-based flow cytometry ${ }^{31}$ but there is no consensus "standard" TF assay. Initial reports suggested a significant association of elevated TF with subsequent VTE ${ }^{31,32}$. However, the majority of these data were derived from patients with specific cancers, particularly pancreas ${ }^{33}$. More recently, in a recent large study of cancer patients with a heterogeneous mix of cancer patients, elevated procoagulant microparticles (albeit not TF-specific) were not found to be predictive of $\mathrm{VTE}^{34}$. Further, in a prospective analysis of subgroups of the Vienna CATS registry, TF was predictive of VTE in pancreatic but not brain or colorectal cancers ${ }^{35}$. TF must therefore still be considered an investigational biomarker, but with potential value in pancreatic and other select cancers.

\section{Risk Assessment Tools}

Risk assessment tools can incorporate multiple variables to identify patients or subpopulations at risk for events. A recently developed risk score can identify cancer patients at high-risk for VTE by utilizing a combination of easily available clinical and laboratory variables (Table 3$)^{23}$. The risk score for VTE was originally derived from a development cohort of 2,701 patients and then validated in an independent cohort of 1,365 patients from a prospective registry. Observed rates of VTE in the development and validation cohorts were $0.8 \%$ and $0.3 \%$ in the low-risk category, $1.8 \%$ and $2 \%$ in the intermediate-risk category and 7.1 and $6.7 \%$ in the high-risk category, respectively. This model was externally validated in a prospective population by the Vienna CATS study in 819 cancer patients ${ }^{36}$. The 6-month cumulative probabilities of developing VTE in this study population were $1.5 \%$ (score of 0 ), $3.8 \%$ (score of 1), $9.4 \%$ (score of 2) and $17.7 \%$ (score 33 ). Several other retrospective and prospective studies have further validated this Risk Score, although rates vary between studies because of varying patient selection and follow-up periods (Table 4). Most recently, the score was found to be the only predictor of VTE in an analysis of 1,412 patients enrolled in phase I studies ${ }^{37}$.

An expansion of the original risk score with the inclusion of two additional biomarkers: Ddimer and soluble P-selectin has been described by the Vienna group ${ }^{36}$. In the expanded risk model, the cumulative VTE probability after 6 months in patients with the highest score ( 25 , $\mathrm{n}=30$ ) was $35.0 \%$ and $10.3 \%$ in those with an intermediate score (score $3, \mathrm{n}=130$ ) as opposed to only $1.0 \%$ in patients with score $0(n=200)$. This expanded risk score, while promising, requires further validation in other studies. The P-selectin assay, required for the expanded model, is not widely available which further limits its practical use.

A myeloma-specific risk assessment algorithm with recommendations for prophylaxis has recently been proposed by the International Myeloma Working Group ${ }^{38}$. Of note, this risk assessment tool is based on expert consensus and has not been validated prospectively or retrospectively. 


\section{PREVENTION}

\section{Hospitalized Medical Cancer Patients}

Three large RCTs in acutely ill medical patients have demonstrated reduced rates of VTE with the use of prophylactic LMWH or fondaparinux (Figure 1) ${ }^{39-41}$. Unfortunately, no cancer-specific RCTs have been conducted. In the medical studies, cancer patients (including those with previous history of cancer) represented only a small minority (5-15\%) of the study population; definition of "active cancer" varied and was unclear; and cancer subgroup data regarding efficacy and safety has not separately been published for all of these studies. Current guidelines recommend thromboprophylaxis, however, based on the known high risk of VTE in the hospitalized cancer population and extrapolation from the data in medical patients ${ }^{42,43}$. Compliance with prophylaxis continues to be an issue. In a recent multinational survey, only $58 \%$ of surgical patients and $39 \%$ of medical patients at risk for VTE received appropriate prophylaxis during hospitalization ${ }^{44}$. Adherence rates were higher in the United States where nearly $60 \%$ of at-risk medical patients received prophylaxis. Utilizing electronic medical records to alert providers is one proven modality to improve compliance. In a study of majority cancer patients, providers were randomized to receiving or not receiving computerized order-entry alerts regarding a patient's risk for VTE and need for prophylaxis ${ }^{45}$. The computer alert not only improved compliance, it also reduced the risk of VTE by $41 \%$ ( $4.9 \%$ VTE in the alert group compared to $8.2 \%$ in controls, HR 0.59; $95 \%$ CI, 0.43 to $0.81 ; \mathrm{P}=0.001)$. A similar reduction in VTE was reported when an order entry alert was introduced into a large tertiary care medical center ${ }^{46}$. These reports therefore provide further (albeit indirect) support for the efficacy of thromboprophylaxis in hospitalized cancer patients.

\section{Surgery and Extended Post-Surgical Period}

Both ASCO and NCCN guidelines recommend thromboprophylaxis in the surgical oncology setting based on multiple randomized studies in patients undergoing cancer surgery, who are at very high risk for $\mathrm{VTE}^{47-50}$. Cancer surgery patients remain at elevated risk for VTE for an extended period of time following hospital discharge ${ }^{16}$. RCTs have shown that extending prophylaxis up to 4 weeks is effective and safe in reducing post-operative VTE ${ }^{51-53}$. Both ASCO and NCCN guidelines recommend that all "high-risk" cancer patients undergoing major abdominopelvic surgery be considered for extended VTE prophylaxis. In the NCCN guidelines, high-risk features in this setting include surgery for gastrointestinal malignancies, prior history of VTE, anesthesia time $>2$ hours, bed rest $>4$ days, advanced stage and age $>60$ years.

\section{Outpatient Chemotherapy}

Most VTE now occurs in the outpatient setting; correspondingly, major recent RCTs have focused on outpatient thromboprophylaxis for solid tumor patients receiving systemic therapy (Figure 1). The Prophylaxis of Thromboembolism during Chemotherapy Trial (PROTECHT) study evaluated the efficacy of daily nadroparin, a LMWH, in "high-risk" sites of cancer, including those with locally advanced or metastatic lung, gastrointestinal, pancreatic, breast, ovarian, and head/neck cancers actively receiving chemotherapy ${ }^{12}$. Event rates were low: $2 \%$ of the treatment group and $3.9 \%$ of the placebo group developed a thromboembolic event (one-sided 95\% CI $0.303 \%, p=0.02$ ) with a non-significant increase in major bleeding. Breast and head/neck cancer patients have not been typically considered high-risk for VTE and their inclusion in this study may have reduced the event rate. The largest study of thromboprophylaxis in cancer to date was recently completed: SAVEONCO was a prospective, double-blind, multicenter study of 3,200 patients with locally advanced or metastatic solid tumors (lung, pancreas, stomach, colorectal, bladder or ovary) randomized to daily subcutaneous semuloparin (a novel ultra-LMWH) or placebo ${ }^{54}$. Patients 
receiving prophylactic semuloparin had $64 \%$ relative risk reduction of VTE (hazard ratio: $0.36 ; 95 \%$ CI $[0.21,0.60] ; \mathrm{p}<0.0001)(1.2$ vs. $3.4 \%)$ compared to placebo with no significant increase in major bleeding. Semuloparin awaits FDA approval for the indication of preventing VTE in cancer patients receiving chemotherapy and is not currently available.

Two other RCTs focused on pancreatic cancer, generally considered a very high risk site for VTE. In the CONKO-004 study (reported only in abstract form thus far), VTE occurred in $5.0 \%$ (8 of 160) of patients randomized to enoxaparin ( $1 \mathrm{mg} / \mathrm{kg}$ daily for 3 months, then 40 $\mathrm{mg}$ daily) versus $14.5 \%$ (22 of 152$)$ in the observation arm $(p<0.01)^{55}$. In the FRAGEM study, 9 patients were randomized to full therapeutic dose of dalteparin versus observation ${ }^{56}$. All-type VTE during the dalteparin treatment period (<100days from randomization) was reduced from $23 \%$ to $3.4 \%$ ( $\mathrm{p}=0.002$ ), an $85 \%$ risk reduction. All-type VTE throughout the whole follow-up period was also reduced from $28 \%$ to $12 \%(\mathrm{p}=0.039)$, a 58\% risk reduction. Lethal VTE (at $<100$ days) was seen only in the control arm, $8.3 \%$ versus $0 \%(\mathrm{p}=0.057), \mathrm{RR}=0.092,95 \% \mathrm{CI}(0.005-1.635)$ but overall survival was no different between the two arms. These studies show that in high-risk patients, extremely high event rates of VTE occur and can safely be reduced. Of note, the CONKO study initially used a higher dose of enoxaparin and the FRAGEM study used the full therapeutic dose of dalteparin whereas SAVE-ONCO and PROTECHT used prophylactic doses.

Myeloma is a high-risk hematologic malignancy for VTE. A recent prospective study addressed the efficacy of thromboprophylaxis with either LMWH or low-dose aspirin or low-fixed dose warfarin in 667 newly diagnosed myeloma patients ${ }^{57}$. In this common substudy of two RCTs, patients treated with one of three specific thalidomide-containing regimens were randomly assigned to receive LMWH (enoxaparin $40 \mathrm{mg} / \mathrm{d}$ ), aspirin (100 $\mathrm{mg} / \mathrm{d}$ ) or warfarin $(1.25 \mathrm{mg} / \mathrm{d})$. The incidence of VTE was $5 \%$ in the LMWH group, $6.4 \%$ in the aspirin group and $8.2 \%$ in the warfarin group (p not significant). Only 3 major bleeding episodes were recorded. The authors concluded that LMWH, warfarin and aspirin are likely to be similarly effective prophylactic regimens, except in elderly patients where warfarin showed less efficacy than LMWH. Aspirin and other anti-platelet agents such as clopidogrel could potentially have anti-thrombotic effects in cancer populations and would be highly cost-effective; however, much more data are necessary than currently available.

Together, these studies demonstrate that outpatient thromboprophylaxis is feasible, safe and effective. However, the low event rate seen in PROTECHT and SAVE-ONCO emphasizes the importance of patient selection and argues against a broad application of prophylaxis for cancer patients. Indeed, when the Risk Score was applied to the SAVE-ONCO population, rates in the placebo arm were higher and risk reduction was therefore greater $(5.4 \%$ in the placebo arm vs $1.4 \%$ in the semuloparin arm, for score $\geq 3$ [HR 0.27] compared to $1.3 \%$ vs. $1 \%$ respectively for score $=0$ [HR 0.71]). Current guidelines have not taken into account these more recent studies and outpatient prophylaxis is currently only recommended by ASCO and NCCN for high-risk myeloma patients receiving thalidomide- or lenalidomidebased combination regimens. NCCN guidelines suggest that prophylaxis be "considered" in other outpatients at risk.

\section{TREATMENT}

VTE in cancer has a different natural history than VTE in non-cancer patients. Patients with cancer-associated VTE have a higher likelihood of both recurrent VTE as well as bleeding and appear more resistant to standard warfarin-based therapy. The risk of recurrence persists in patients with active malignancy. Therefore, treatment recommendations for cancerassociated VTE are necessarily different from VTE in the general population. Where possible, these should rely on cancer-specific studies and should not be extrapolated from 
larger studies of the general populations. A summary of the recommendations for treatment of VTE in cancer by the ASCO and NCCN guidelines panels is provided in Table 4.

Based on the results of several randomized trials and meta-analyses, LMWHs are recommended for the initial treatment of VTE in cancer patients ${ }^{58}$. Fondaparinux is also an acceptable agent to use in initial treatment. ${ }^{59}$. Warfarin has long been the standard anticoagulant for long-term treatment and prevention of VTE. However, LMWHs offer several advantages in cancer patients. A retrospective study of over 800 patients being treated with standard oral anticoagulation demonstrated significantly higher rates of recurrent VTE (20\% vs 6\%) and major bleeding (12\% vs 5\%) in patients with cancer compared to those without cancer ${ }^{4}$. These findings could not be explained by suboptimal anticoagulation. Of note, the increased bleeding events do not appear to be associated with supratherapeutic anticoagulation as shown in a prospective study 60 .

The most robust evidence to recommend LMWHs for extended therapy comes from the CLOT trial. This study randomized 676 cancer patients with VTE to receive initial dalteparin followed by 6 months of either dalteparin or warfarin with target INR $2.5^{61}$. Fifteen percent of patients treated with warfarin developed recurrent VTE compared to 7.9\% of patients treated with dalteparin (HR 0.48, 95\% CI 0.30-0.77). This translates into an absolute risk reduction of $7.8 \%$ or a number needed to treat of 12 to prevent one recurrent VTE. This landmark trial established the superiority of LMWH for long-term anticoagulation in cancer patients. Other smaller studies with tinzaparin and enoxaparin and a Cochrane systematic review all support the use of LMWH in the treatment of cancerassociated VTE ${ }^{62}$. Clinical practice guidelines issued by ASCO and NCCN therefore recommend long-term anticoagulation with LMWH for cancer patients with VTE as the preferred approach.

\section{Duration of Anticoagulation}

The optimal duration of anticoagulation in cancer patients with VTE is not known. Theoretically many cancer patients with active cancer have a persistent risk for thrombosis thus extended anticoagulation beyond the standard 6 months should be considered especially for those with cancer and/or receiving anti-cancer treatments. Thereafter, the risk-benefit ratio should be weighed periodically and a case-by-case decision regarding the duration of anticoagulation is recommended.

\section{Recurrent VTE on Anticoagulation}

Management of recurrent cancer-associated VTE on anticoagulation is a vexing and not infrequent clinical problem with no evidence-based data to guide clinical management. In general, patients who are being anticoagulated with warfarin (despite recommendation for LMWH) should be switched to LMWH therapy. For those patients already on LMWH anticoagulation, dose escalation may be beneficial. The best evidence for this approach comes from a retrospective cohort study ${ }^{63}$. Patients on therapeutic dose of LMWH were managed by increasing the weight-adjusted dose by $20-25 \%$ for at least 4 weeks. Patients on maintenance dose of LMWH were increased to full therapeutic dose for 6-12 weeks. Only $8.6 \%$ of patients had a second recurrent VTE with this approach and $4.3 \%$ had bleeding complications. The authors suggest that dose escalating LWMH is an effective way of managing recurrent VTE in this setting.

Inferior vena caval filters should be used conservatively and only temporarily in situations with serious contraindication to anti-coagulation. The PREPIC study is currently the only reported randomized trial to assess use of vena caval filters ${ }^{64}$. In this prospective study of 200 patients (including 56 with cancer) on anticoagulation, those who received a filter had 
short-term protection from PE but suffered significantly more recurrent DVT and filter-site thrombosis compared to those who did not have filters placed (20.8\% vs. $11.6 \%$, OR 1.87 , $95 \%$ CI $1.10-1.38$ ). ASCO guidelines recommend insertion of a vena cava filter only for patients with contraindications to anticoagulant therapy or in those with recurrent VTE despite adequate long-term therapy with LMWH.

\section{FUTURE DIRECTIONS}

Although important strides have been made in understanding cancer-associated thrombosis in the past decade, much remains to be learnt. Ongoing registry and biomarker studies are focused on risk assessment. Clinical trials are currently focused on outpatient prophylaxis of ambulatory cancer patients. The University of Rochester and Duke University are conducting an NIH-sponsored randomized study based on the risk score in which cancer outpatients at high risk for VTE (risk score 23 ) receive thromboprophylaxis with dalteparin or observation for 12 weeks, in addition to chemotherapy (Clinicaltrials.gov NCT00876915). The MicroTEC study is investigating enoxaparin in patients with pancreatic, lung and colorectal cancer with elevated plasma TF microparticles (Clinicaltrials.gov NCT00908960). Novel oral anticoagulants are now available worldwide for specific prophylactic indications in the non-cancer setting. A major advantage of these agents is their oral formulation, which will likely increase acceptability for long-term use. Currently, however, no published data in cancer-specific populations are available with the exception of an early-phase dose-finding study of apixaban. The knowledge gained from ongoing and planned studies will hopefully allow clinicians to identify individual patients at risk for VTE, target such patients with safe, effective and patient-friendly thromboprophylaxis and, above all, reduce the burden and consequences associated with VTE in cancer.

\section{Acknowledgments}

Dr. Khorana is supported by grants from the National Cancer Institute (K23 CA120587), the National Heart, Lung and Blood Institute (R01HL095109) and the V Foundation.

\section{References}

1. Khorana AA, Francis CW, Culakova E, et al. Frequency, risk factors, and trends for venous thromboembolism among hospitalized cancer patients. Cancer. 2007; 110:2339-2346. [PubMed: 17918266]

2. Moore RA, Adel N, Riedel E, et al. High incidence of thromboembolic events in patients treated with Cisplatin-based chemotherapy: a large retrospective analysis. J Clin Oncol. 29:3466-73. [PubMed: 21810688]

3. Khorana AA, Dalal M, Lin J, et al. Venous thromboembolism in the cancer outpatient setting: contemporary rates and predictors in the United States. Journal of Thrombosis and Haemostasis OMO-131. 2011

4. Prandoni P, Lensing AW, Piccioli A, et al. Recurrent venous thromboembolism and bleeding complications during anticoagulant treatment in patients with cancer and venous thrombosis. Blood. 2002; 100:3484-8. [PubMed: 12393647]

5. Sorensen HT, Mellemkjaer L, Olsen JH, et al. Prognosis of cancers associated with venous thromboembolism. N Engl J Med. 2000; 343:1846-50. [PubMed: 11117976]

6. Khorana AA, Francis CW, Culakova E, et al. Thromboembolism is a leading cause of death in cancer patients receiving outpatient chemotherapy. J Thromb Haemost. 2007; 5:632-4. [PubMed: 17319909]

7. Khorana AA. Venous thromboembolism and prognosis in cancer. Thromb Res.

8. Elting LS, Escalante CP, Cooksley C, et al. Outcomes and cost of deep venous thrombosis among patients with cancer. Arch Intern Med. 2004; 164:1653-61. [PubMed: 15302635] 
9. Khorana AA, Connolly GC. Assessing risk of venous thromboembolism in the patient with cancer. J Clin Oncol. 2009; 27:4839-47. [PubMed: 19720906]

10. Reynolds MW, Shibata A, Zhao S, et al. Impact of clinical trial design and execution-related factors on incidence of thromboembolic events in cancer patients: a systematic review and metaanalysis. Curr Med Res Opin. 2008; 24:497-505. [PubMed: 18194590]

11. Mandala M, Barni S, Floriani I, et al. Incidence and clinical implications of venous thromboembolism in advanced colorectal cancer patients: the 'GISCAD-alternating schedule' study findings. Eur J Cancer. 2009; 45:65-73. [PubMed: 19068274]

12. Agnelli G, Gussoni G, Bianchini C, et al. Nadroparin for the prevention of thromboembolic events in ambulatory patients with metastatic or locally advanced solid cancer receiving chemotherapy: a randomised, placebo-controlled, double-blind study. Lancet Oncol. 2009; 10:943-9. [PubMed: 19726226]

13. Agnelli G, George DJ, Fisher W, Kakkar AK, Lassen MR, Mismetti P, Mouret P, Chaudhari U, Turpie AG. The ultra-low molecular weight heparin (ULMWH) semuloparin for prevention of venous thromboembolism (VTE) in patients with cancer receiving chemotherapy: SAVE ONCO study. J Clin Oncol. 2011 ASCO Annual Meeting 29:Abstract No: LBA9014 2011.

14. Khorana AA, Francis CW, Culakova E, et al. Thromboembolism in hospitalized neutropenic cancer patients. Journal of clinical oncology : official journal of the American Society of Clinical Oncology. 2006; 24:484-490. [PubMed: 16421425]

15. Blom JW, Doggen CJ, Osanto S, et al. Malignancies, prothrombotic mutations, and the risk of venous thrombosis. Jama. 2005; 293:715-22. [PubMed: 15701913]

16. Agnelli G, Bolis G, Capussotti L, et al. A clinical outcome-based prospective study on venous thromboembolism after cancer surgery: the @ RISTOS project. Ann Surg. 2006; 243:89-95. [PubMed: 16371741]

17. Kroger K, Weiland D, Ose C, et al. Risk factors for venous thromboembolic events in cancer patients. Ann Oncol. 2006; 17:297-303. [PubMed: 16282243]

18. Heit JA, Silverstein MD, Mohr DN, et al. Risk factors for deep vein thrombosis and pulmonary embolism: a population-based case-control study. Arch Intern Med. 2000; 160:809-15. [PubMed: 10737280]

19. Blom JW, Vanderschoot JP, Oostindier MJ, et al. Incidence of venous thrombosis in a large cohort of 66,329 cancer patients: results of a record linkage study. J Thromb Haemost. 2006; 4:529-35. [PubMed: 16460435]

20. Scappaticci FA, Skillings JR, Holden SN, et al. Arterial thromboembolic events in patients with metastatic carcinoma treated with chemotherapy and bevacizumab. J Natl Cancer Inst. 2007; 99:1232-9. [PubMed: 17686822]

21. Nalluri SR, Chu D, Keresztes R, et al. Risk of venous thromboembolism with the angiogenesis inhibitor bevacizumab in cancer patients: a meta-analysis. JAMA. 2008; 300:2277-85. [PubMed: 19017914]

22. Choueiri TK, Schutz FA, Je Y, et al. Risk of arterial thromboembolic events with sunitinib and sorafenib: a systematic review and meta-analysis of clinical trials. J Clin Oncol. 28:2280-5. [PubMed: 20351323]

23. Khorana AA, Kuderer NM, Culakova E, et al. Development and validation of a predictive model for chemotherapy-associated thrombosis. Blood. 2008; 111:4902-7. [PubMed: 18216292]

24. Starling N, Rao S, Cunningham D, et al. Thromboembolism in patients with advanced gastroesophageal cancer treated with anthracycline, platinum, and fluoropyrimidine combination chemotherapy: a report from the UK National Cancer Research Institute Upper Gastrointestinal Clinical Studies Group. J Clin Oncol. 2009; 27:3786-93. [PubMed: 19398575]

25. Stender MT, Frokjaer JB, Larsen TB, et al. Preoperative plasma D-dimer is a predictor of postoperative deep venous thrombosis in colorectal cancer patients: a clinical, prospective cohort study with one-year follow-up. Dis Colon Rectum. 2009; 52:446-51. [PubMed: 19333044]

26. Ay C, Vormittag R, Dunkler D, et al. D-dimer and prothrombin fragment $1+2$ predict venous thromboembolism in patients with cancer: results from the Vienna Cancer and Thrombosis Study. J Clin Oncol. 2009; 27:4124-9. [PubMed: 19636003] 
27. Kasthuri RS, Taubman MB, Mackman N. Role of tissue factor in cancer. J Clin Oncol. 2009; 27:4834-8. [PubMed: 19738116]

28. Khorana AA, Ahrendt SA, Ryan CK, et al. Tissue factor expression, angiogenesis, and thrombosis in pancreatic cancer. Clinical Cancer Research. 2007; 13:2870-5. [PubMed: 17504985]

29. Khorana AA, Francis CW, Menzies KE, et al. Plasma tissue factor may be predictive of venous thromboembolism in pancreatic cancer. Journal of Thrombosis \& Haemostasis. 2008; 6:1983-5. [PubMed: 18795992]

30. Tilley RE, Holscher T, Belani R, et al. Tissue factor activity is increased in a combined platelet and microparticle sample from cancer patients. Thrombosis research. 2008; 122:604-9. [PubMed: 18262600]

31. Zwicker JI, Liebman HA, Neuberg D, et al. Tumor-derived tissue factor-bearing microparticles are associated with venous thromboembolic events in malignancy. Clin Cancer Res. 2009; 15:6830 40. [PubMed: 19861441]

32. Khorana AA, Francis CW, Menzies KE, et al. Plasma tissue factor may be predictive of venous thromboembolism in pancreatic cancer. J Thromb Haemost. 2008; 6:1983-5. [PubMed: 18795992]

33. Khorana AA, Ahrendt SA, Ryan CK, et al. Tissue factor expression, angiogenesis, and thrombosis in pancreatic cancer. Clin Cancer Res. 2007; 13:2870-5. [PubMed: 17504985]

34. Thaler J, Ay C, Weinstabl H, et al. Circulating procoagulant microparticles in cancer patients. Ann Hematol.

35. Ay C, Mackman N, Key NS, et al. Microparticle-associated tissue factor activity and occurrence of venous thromboembolism in brain, gastrointestinal and pancreatic cancer. Journal of Thrombosis and Haemostasis O-MO-133. 2011

36. Ay C, Dunkler D, Marosi C, et al. Prediction of venous thromboembolism in cancer patients. Blood. 116:5377-82. [PubMed: 20829374]

37. Mandala M, Clerici M, Corradino I, et al. Incidence, risk factors and clinical implications of venous thromboembolism in cancer patients treated within the context of phase I studies: the 'SENDO experience'. Ann Oncol.

38. Palumbo A, Rajkumar SV, Dimopoulos MA, et al. Prevention of thalidomide- and lenalidomideassociated thrombosis in myeloma. Leukemia. 2008; 22:414-23. [PubMed: 18094721]

39. Samama MM, Cohen AT, Darmon J-Y, et al. A Comparison of Enoxaparin with Placebo for the Prevention of Venous Thromboembolism in Acutely ILL Medical Patients. The New England Journal of Medicine. 1999; 341(11):793-800. [PubMed: 10477777]

40. Leizorovicz A, Cohen AT, Turpie AG, et al. Randomized, placebo-controlled trial of dalteparin for the prevention of venous thromboembolism in acutely ill medical patients. Circulation. 2004; 110:874-9. [PubMed: 15289368]

41. Cohen AT, Davidson BL, Gallus AS, et al. Efficacy and safety of fondaparinux for the prevention of venous thromboembolism in older acute medical patients: randomised placebo controlled trial. Bmj. 2006; 332:325-9. [PubMed: 16439370]

42. Lyman GH, Khorana AA, Falanga A, et al. American Society of Clinical Oncology Guideline: Recommendations for Venous Thromboembolism Prophylaxis and Treatment in Patients With Cancer. J Clin Oncol. 2007

43. Wagman LD, Baird MF, Bennett CL, et al. Venous thromboembolic disease. NCCN Clinical practice guidelines in oncology J Natl Compr Canc Netw. 2008; 6:716-53.

44. Cohen AT, Tapson VF, Bergmann JF, et al. Venous thromboembolism risk and prophylaxis in the acute hospital care setting (ENDORSE study): a multinational cross-sectional study. Lancet. 2008; 371:387-94. [PubMed: 18242412]

45. Kucher N, Koo S, Quiroz R, et al. Electronic alerts to prevent venous thromboembolism among hospitalized patients. N Engl J Med. 2005; 352:969-77. [PubMed: 15758007]

46. Candelario GD, Francis CW, Panzer R, et al. A Computerized Prompt for Thromboprophylaxis in Hospitalized Cancer Patients. Thromb Res. 2009

47. Efficacy and safety of enoxaparin versus unfractionated heparin for prevention of deep vein thrombosis in elective cancer surgery: a double-blind randomized multicentre trial with venographic assessment. ENOXACAN Study Group. Br J Surg. 1997; 84:1099-103. [PubMed: 9278651] 
48. McLeod RS, Geerts WH, Sniderman KW, et al. Subcutaneous heparin versus low-molecularweight heparin as thromboprophylaxis in patients undergoing colorectal surgery: results of the canadian colorectal DVT prophylaxis trial: a randomized, double-blind trial. Ann Surg. 2001; 233:438-44. [PubMed: 11224634]

49. Agnelli G, Bergqvist D, Cohen AT, et al. Randomized clinical trial of postoperative fondaparinux versus perioperative dalteparin for prevention of venous thromboembolism in high-risk abdominal surgery. Br J Surg. 2005; 92:1212-20. [PubMed: 16175516]

50. Akl EA, Terrenato I, Barba M, et al. Low-molecular-weight heparin vs unfractionated heparin for perioperative thromboprophylaxis in patients with cancer: a systematic review and meta-analysis. Arch Intern Med. 2008; 168:1261-9. [PubMed: 18574082]

51. Bergqvist D, Agnelli G, Cohen AT, et al. Duration of prophylaxis against venous thromboembolism with enoxaparin after surgery for cancer. N Engl J Med. 2002; 346:975-80. [PubMed: 11919306]

52. Rasmussen MS, Jorgensen LN, Wille-Jorgensen P, et al. Prolonged prophylaxis with dalteparin to prevent late thromboembolic complications in patients undergoing major abdominal surgery: a multicenter randomized open-label study. J Thromb Haemost. 2006; 4:2384-90. [PubMed: 16881934]

53. Kakkar VV, Balibrea JL, Martinez-Gonzalez J, et al. Extended prophylaxis with bemiparin for the prevention of venous thromboembolism after abdominal or pelvic surgery for cancer: the CANBESURE randomized study. J Thromb Haemost. 8:1223-9. [PubMed: 20456751]

54. Agnelli G, George DJ, Fisher W, Kakkar AK, Lassen MR, Mismetti P, Mouret P, Chaudhari U, Turpie AG. The ultra-low molecular weight heparin (ULMWH) semuloparin for prevention of venous thromboembolism (VTE) in patients with cancer receiving chemotherapy: SAVE ONCO study. J Clin Oncol. 2011 ASCO Annual Meeting 29:Abstract No: LBA9014 2011.

55. Riess UP, Deutschinoff G, Opitz B, Stauch M, Reitzig P, Hahnfeld S, Hilbig A, Stieler J, Oettle H. A prospective, randomized trial of chemotherapy with or without the low molecular weight heparin (LMWH) enoxaparin in patients (pts) with advanced pancreatic cancer (APC): Results of the CONKO 004 trial. Journal of Clinical Oncology. 2009:27. 2009 ASCO Annual Meeting Proceedings (Post-Meeting Edition).

56. Maraveyas A, Waters J, Roy R, et al. Gemcitabine versus gemcitabine plus dalteparin thromboprophylaxis in pancreatic cancer. Eur J Cancer.

57. Palumbo A, Cavo M, Bringhen S, et al. Aspirin, warfarin, or enoxaparin thromboprophylaxis in patients with multiple myeloma treated with thalidomide: a phase III, open-label, randomized trial. J Clin Oncol. 29:986-93. [PubMed: 21282540]

58. Gould MK, Dembitzer AD, Doyle RL, et al. Low-molecular-weight heparins compared with unfractionated heparin for treatment of acute deep venous thrombosis. A meta-analysis of randomized, controlled trials. Ann Intern Med. 1999; 130:800-9. [PubMed: 10366369]

59. Buller HR, Davidson BL, Decousus H, et al. Subcutaneous fondaparinux versus intravenous unfractionated heparin in the initial treatment of pulmonary embolism. N Engl J Med. 2003; 349:1695-702. [PubMed: 14585937]

60. Palareti G, Legnani C, Lee A, et al. A comparison of the safety and efficacy of oral anticoagulation for the treatment of venous thromboembolic disease in patients with or without malignancy. Thromb Haemost. 2000; 84:805-10. [PubMed: 11127860]

61. Lee AY, Levine MN, Baker RI, et al. Low-molecular-weight heparin versus a coumarin for the prevention of recurrent venous thromboembolism in patients with cancer. N Engl J Med. 2003; 349:146-53. [PubMed: 12853587]

62. Akl EA, Barba M, Rohilla S, et al. Low-Molecular-Weight Heparins are superior to Vitamin K Antagonists for the long term treatment of venous thromboembolism in patients with cancer: a Cochrane systematic review. J Exp Clin Cancer Res. 2008; 27:21. [PubMed: 18634550]

63. Carrier M, Le Gal G, Cho R, et al. Dose escalation of low molecular weight heparin to manage recurrent venous thromboembolic events despite systemic anticoagulation in cancer patients. $\mathrm{J}$ Thromb Haemost. 2009; 7:760-5. [PubMed: 19245418]

64. Decousus H, Leizorovicz A, Parent F, et al. A clinical trial of vena caval filters in the prevention of pulmonary embolism in patients with proximal deep-vein thrombosis. Prevention du Risque 
d'Embolie Pulmonaire par Interruption Cave Study Group. N Engl J Med. 1998; 338:409-15. [PubMed: 9459643]

65. Ay C, Simanek R, Vormittag R, et al. High plasma levels of soluble P-selectin are predictive of venous thromboembolism in cancer patients: results from the Vienna Cancer and Thrombosis Study (CATS). Blood. 2008; 112:2703-8. [PubMed: 18539899]

66. Vormittag R, Simanek R, Ay C, et al. High factor VIII levels independently predict venous thromboembolism in cancer patients: the cancer and thrombosis study. Arterioscler Thromb Vasc Biol. 2009; 29:2176-81. [PubMed: 19778945]

67. Kearney JC, Rossi S, Glinert K, et al. Venous thromboembolism (VTE) and survival in a cancer chemotherapy outpatient clinic: a retrospective chart validation of a VTE prediction model. Blood. 2009:2503. abstract.

68. Price LH, Nguyen MB, Picozzi VJ, et al. Portal vein thrombosis in pancreatic cancer: natural history, risk factors and implications for patient management. 2010 Gastrointestinal Cancer Symposium Program and Proceedings Abstract 143. 2010

69. Khorana AA, Herman K, Rubens D, et al. A Predictive Risk Score for Cancer-Associated Thrombosis: Role of Screening in A Prospective Study. Blood. 2010 Abstract 3173. 


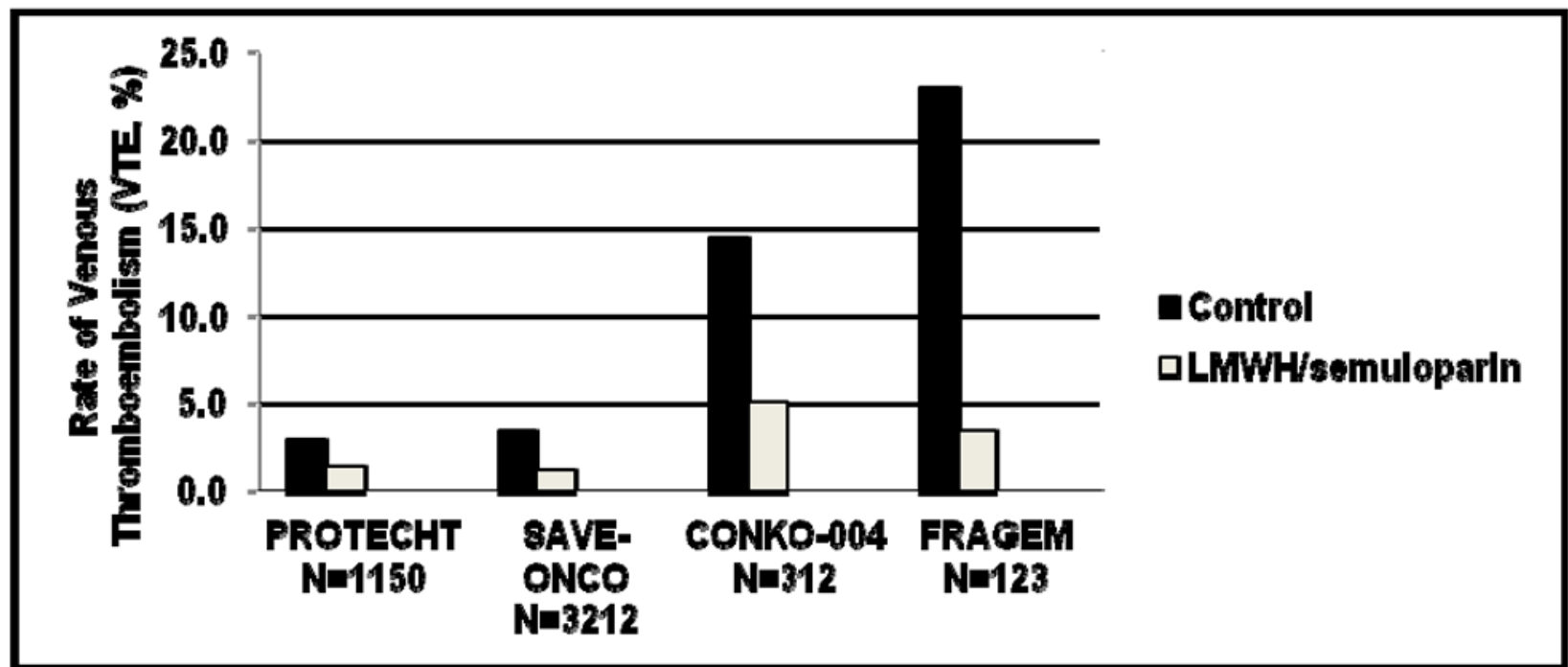

Figure 1. Thromboprophylaxis in the Outpatient Setting

Rates of VTE (\%) in four recent RCTs of LMWH prophylaxis in patients with solid tumors are shown. These included PROTECHT $(\mathrm{P}=0.02)$ and SAVE-ONCO (both included various locally advanced or metastatic solid tumors) and CONKO-004 $(\mathrm{P}<0.01)$ and FRAGEM $(\mathrm{P}=$ 0.019 ) both included advanced pancreatic cancers only). 
Table 1

Selected Clinical Risk Factors and Biomarkers for Cancer-associated Thrombosis

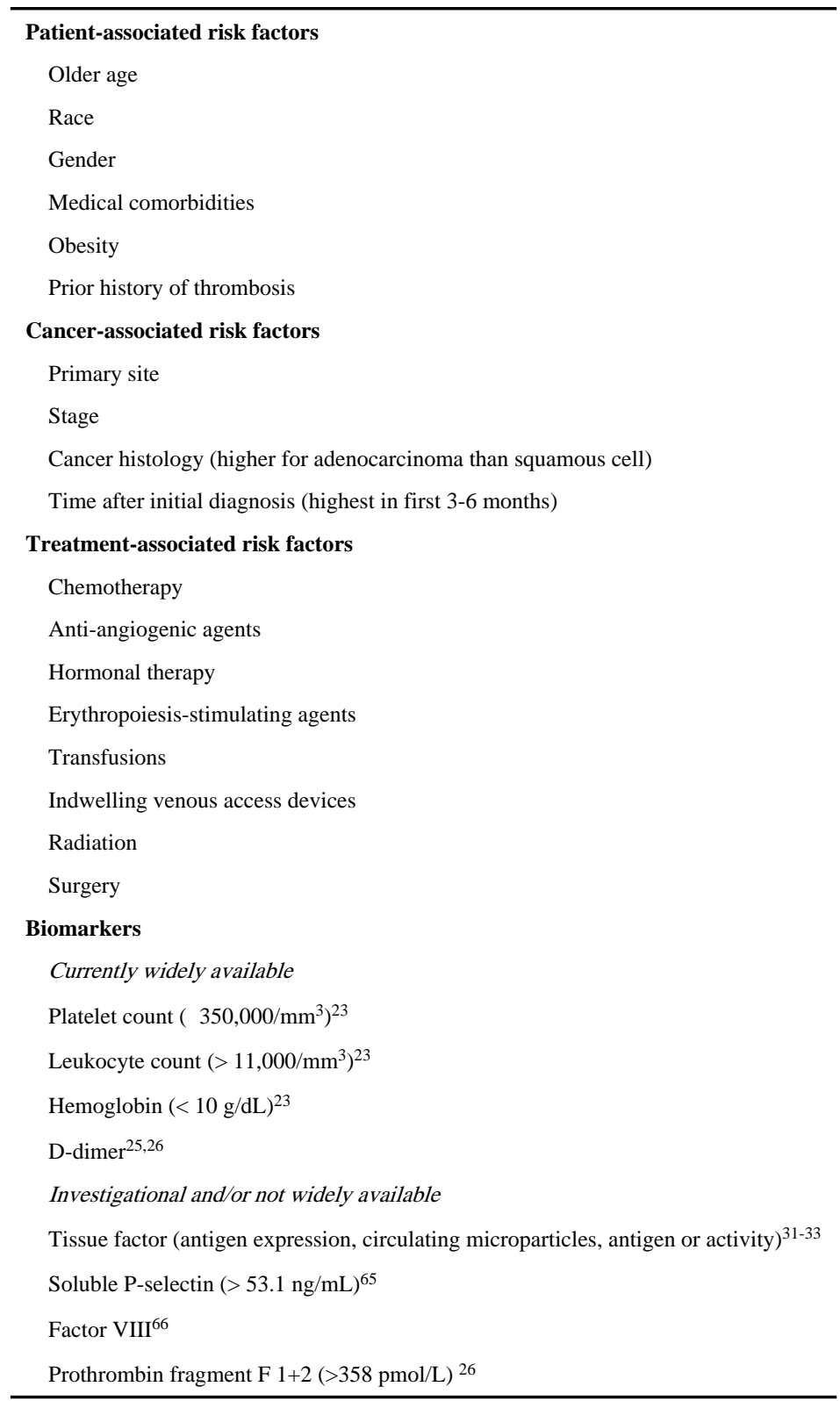


Table 2

Predictive Model for chemotherapy-associated VTE ${ }^{23}$

\begin{tabular}{|c|c|}
\hline Patient Characteristics & Risk Score \\
\hline \multicolumn{2}{|l|}{ Site of cancer } \\
\hline Very high risk (stomach, pancreas) & 2 \\
\hline High risk (lung, lymphoma, gynecologic, bladder, testicular) & 1 \\
\hline Prechemotherapy platelet count $350000 / \mathrm{mm}^{3}$ or more & 1 \\
\hline Hemoglobin level less than $10 \mathrm{~g} / \mathrm{dl}$ or use of red cell growth factors & 1 \\
\hline Prechemotherapy leukocyte count more than $11000 / \mathrm{mm}^{3}$ & 1 \\
\hline Body mass index $35 \mathrm{~kg} / \mathrm{m}^{2}$ or more & 1 \\
\hline
\end{tabular}

High-risk score $\geq 3$

Intermediate risk score $=1-2$

Low-risk score $=0$ 


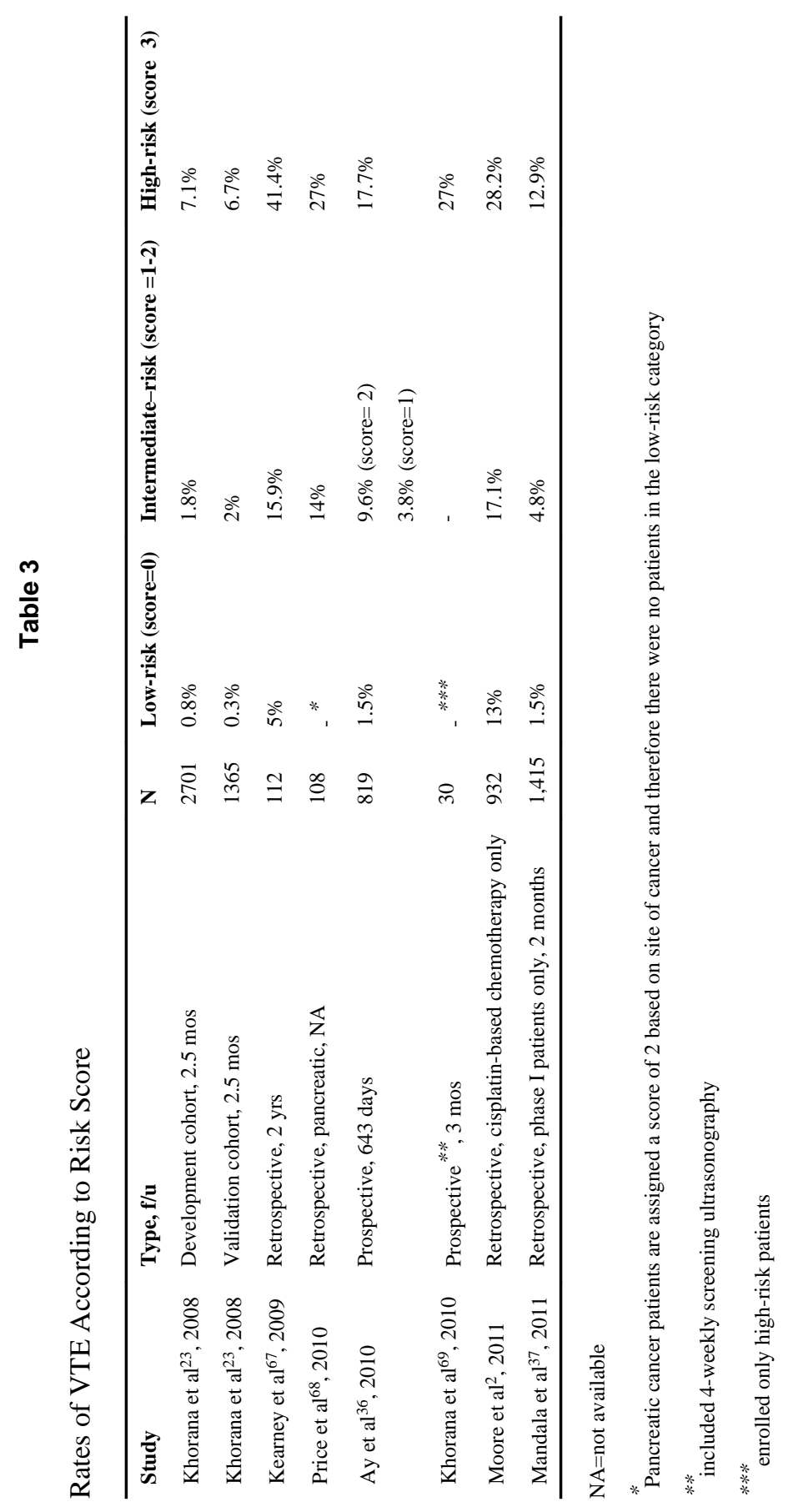

Am J Hematol. Author manuscript; available in PMC 2013 May 01. 
Table 4

ASCO and NCCN Recommendations for Treatment of VTE in Cancer

\begin{tabular}{|c|c|}
\hline ASCO & $\mathbf{N C C N}$ \\
\hline \multicolumn{2}{|l|}{ Initial treatment } \\
\hline LMWH is the preferred approach for the initial 5-10 days & $\begin{array}{l}\text { LMWH, UFH or factor Xa antagonists according to patient's characteristics and } \\
\text { clinical situation }\end{array}$ \\
\hline \multicolumn{2}{|l|}{ Long term treatment } \\
\hline LMWH for at least 6 months is preferred. & LMWH is preferred \\
\hline VKA are acceptable when LMWH is not available. & Indefinite anticoagulation in patients with active cancer or persistent risk factors \\
\hline Indefinite anticoagulation in patients with active cancer. & \\
\hline \multicolumn{2}{|l|}{ Thrombolytic therapy in initial treatment } \\
\hline $\begin{array}{l}\text { Restricted to patients with life- or limb-threatening } \\
\text { thrombotic events }\end{array}$ & $\begin{array}{l}\text { Restricted to massive or submassive PE with moderate or severe right } \\
\text { ventricular enlargement or dysfunction }\end{array}$ \\
\hline \multicolumn{2}{|l|}{ Inferior vena cava filters } \\
\hline $\begin{array}{l}\text { Restricted to patients with contraindications to } \\
\text { anticoagulation or recurrent VTE despite adequate long- } \\
\text { term LMWH }\end{array}$ & $\begin{array}{l}\text { Restricted to patients with contraindications to or failure of anticoagulation, } \\
\text { cardiac or pulmonary dysfunction severe enough to make any new PE life- } \\
\text { threatening or multiple PE with chronic pulmonary hypertension }\end{array}$ \\
\hline \multicolumn{2}{|l|}{ Treatment of catheter-related thrombosis } \\
\hline NA & $\begin{array}{l}\text { LMWH or VKA for as long as catheter is in place or for } 1 \text { to } 3 \text { months after } \\
\text { catheter removal }\end{array}$ \\
\hline
\end{tabular}

